\title{
Corrigendum
}

\section{Molecular analysis of a novel glutamine synthetase of the anaerobe Bacteroides fragilis}

\section{Russell T. Hill, Joan R. Parker, Heide J. K. Goodman, David T. Jones} and DAVID R. WOOD.

Journal of General Microbiology (1989), 135, 3271-3279.

Fig. 3, p. 3275:

This figure was incorrectly printed: all the dots in the lower two panels, and some of those in the upper two panels, were omitted. The correct version is shown below.
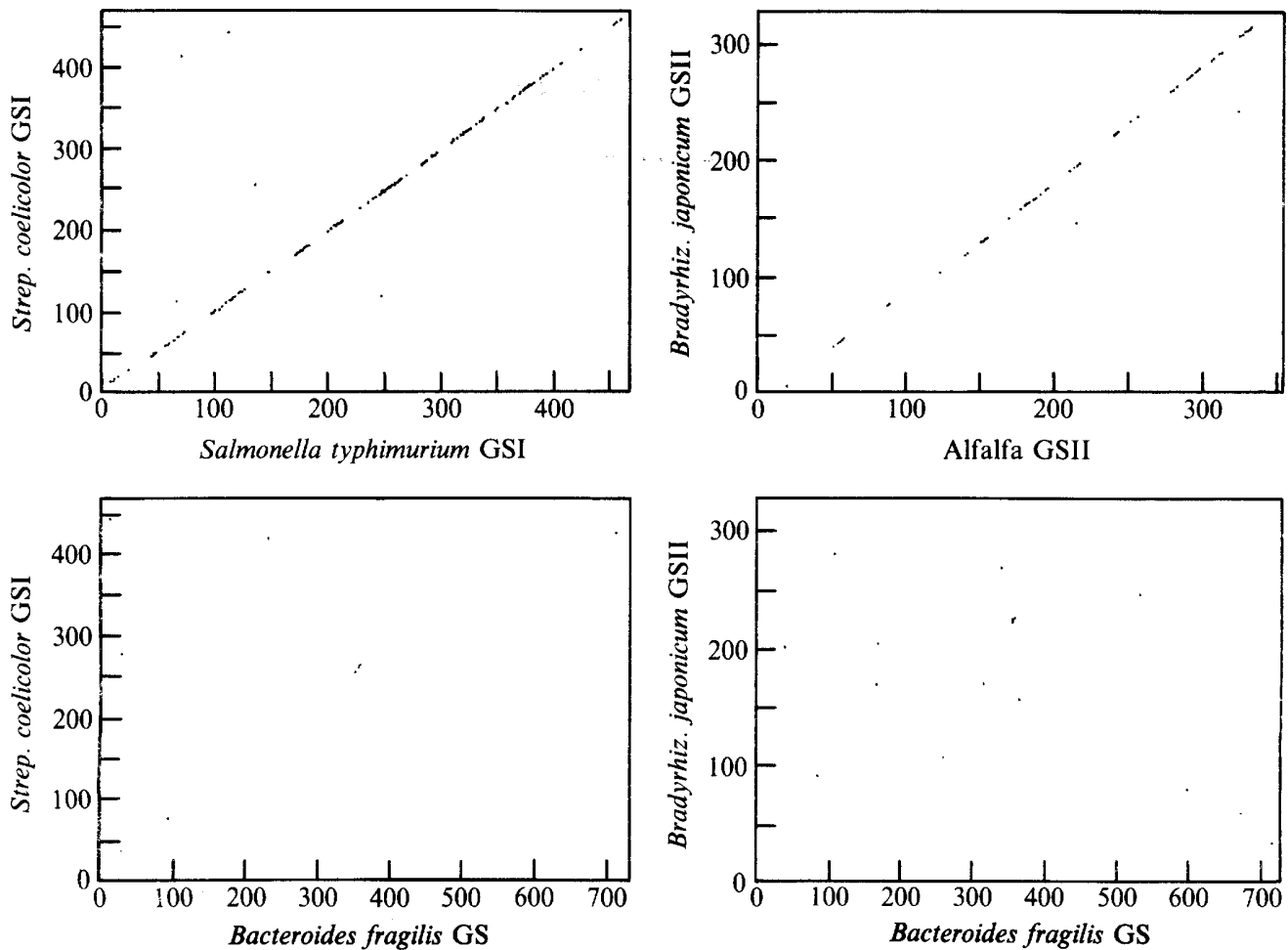

Fig. 3. Dot-matrix comparisons of amino acid sequences of GSI enzymes from Salmonella typhimurium and Streptomyces coelicolor, of GSII enzymes from alfalfa and Bradyrhizobium japonicum, and of the Bacteroides fragilis GS with a GSI enzyme and a GSII enzyme. Dot-matrix comparisons were done using the GENEPRO (version 3.1) sequence analysis program (Riverside Scientific), checking for five matches in a window of ten residues. 